\title{
Tracheal Disorder
}

National Cancer Institute

\section{Source}

National Cancer Institute. Tracheal Disorder. NCI Thesaurus. Code C35079.

A non-neoplastic or neoplastic disorder that affects the trachea. Representative examples of non-neoplastic disorders include congenital malformations and infection.

Representative examples of neoplastic disorders include carcinoma and lymphoma. 